\title{
WHEAT GERM OIL ATTENUATES CYCLOSPORIN A-INDUCED RENAL INJURY IN RATS VIA INHIBITION OF ROS, INOS, AND NF-kB EXPRESSION
}

\author{
BY \\ Amany Balah \\ FROM \\ Pharmacology and Toxicology Department, Faculty of Pharmacy (Girls), \\ Al-Azhar University, Cairo, Egypt
}

\begin{abstract}
Cyclosporin A (CsA) is one of the most efficient immunosuppressive drugs that are widely used in organ transplantation. However, its clinical use is often limited by acute and chronic nephrotoxicity. One of the possible mechanisms of CsA-induced nephrotoxicity is thought to be reactive oxygen species (ROS) formation. The present work was designed to investigate the potential protective effect of wheat germ oil (WGO) as antioxidant on CsAinduced nephrotoxicity in rats. It was found that treatment of animals with CsA alone significantly increased the levels of blood urea nitrogen and serum creatinine. In addition, CsA has also reduced the renal content of reduced glutathione, as well as the enzymatic activities of superoxide dismutase and catalase. Furthermore, these effects were associated with an increase in lipid peroxidation, inducible NO-synthase (iNOS), and NF- $\mathrm{BB}$ expression. Moreover, histopathological examination showed severe damage of the renal tissue in animals treated with CsA alone. The present work demonstrates that administration of WGO 5 days before and concurrently during CsA administration ameliorated all these negative effects and improved renal function via inhibition of ROS, iNOS and NF- $\kappa \mathrm{B}$ expression. Most interestingly, the immunosuppressive effect of CsA has not been affected by WGO.
\end{abstract}

\section{INTRODUCTION}

Organ transplantation is one of the most miraculous achievements in modern medicine due to its contribution in decreasing the mortality rate of patients with organs failure. However, the risk of transplant rejection threatens the success of the transplantation process. Transplant rejection can be prevented by the use of an immunosuppressive agent to suppress the reaction of the immune system to the transplanted tissue. Cyclosporin A (CsA) is one of the calcineurin inhibitors that suppress T-cell activation by inhibiting the cellular phosphatase calcineurin (Schreiber and Crabtree, 1992). Calcineurin inhibitors (CNI) are among the most efficient immunosuppressive drugs and therefore are widely used in transplantation and for the treatment of many inflammatory diseases including psoriasis, and rheumatoid arthritis. However, the clinical use of the calcineurin inhibitor CsA is strongly limited by acute and chronic nephrotoxicity which remain a major clinical problem (Mihatsch et al., 1998; Fellstrom, 2004). The mechanisms of CsA-induced renal injury are not fully elucidated. However, one of the possible mechanisms of CsA-induced nephrotoxicity is thought to be over production of reactive oxygen species (ROS) and a consequent imbalance between oxidants and endogenously produced antioxidants (Ichikawa et al., 1994; Serino et al., 1994; 
Akool et al., 2008). The harmful effects induced by CsA can be antagonized by using a powerful antioxidant agent (Tariq et al., 1999; Uz et al., 2011). Wheat germ oil (WGO) is the richest known natural source of vitamin E (Shurpalekar and Rao, 1977). In addition to the most powerful natural antioxidant vitamin E (Wolf et al., 1998; Ohkatsu et al., 2001), WGO is also rich in unsaturated fatty acids, mainly oleic, and $\alpha$-linoleic acids that may exert inhibition of oxidative stress (Sjovall et al., 2000; Alessandri et al., 2006). Furthermore, WGO is rich in functional phytochemicals, mainly flavonoids, sterols, octacosanols and glutathione (Zhu et al., 2006). Recently, it has been reported that WGO intake results in a rapid increase in the content of vitamin $\mathrm{E}$ in different rat tissues and exerts high protection against oxidative damage (Mehranjani et al., 2007; Field et al., 2008). Thus it was interesting to investigate the potential protective effect of WGO against CsA-induced nephrotoxicity in rats.

\section{MATERIALS AND METHODS}

\section{Animals}

Twenty-four male Wistar albino rats weighing 200-250 g were housed in a $12 \mathrm{~h}$ dark/light cycle animal facility with controlled humidity and constant temperature. The animals were fed a standard diet and water was supplied ad libitum. The animals were kept under observation for one week before the treatments for adaptation. The experimental protocol used in this study was approved by the Institutional Animal Ethics Committee.

\section{Drugs and Chemicals}

CsA was purchased from Sandoz Ltd, Basel, Switzerland. WGO was purchased from SEDICO Pharmaceutical Co., 6 October City, Egypt. Inducible NO-synthase (iNOS), Nuclear factor kappa-B (NF- $\kappa \mathrm{B})$, and catalase (CAT) ELISA kits were purchased from EIAab Science Co., Ltd., China. Reduced glutathione (GSH), Superoxide dismutase (SOD), and thiobarbituric acid reactive substances (TBARS) assay kits were purchased from Oxford biomedical research (Oxford MI, USA), Trevigen (USA), and Cell Biolabs (USA) respectively. Interleukin-2 (IL-2) ELISA kit was purchased from Uscn Life Science Inc, Wuhan, China. Blood urea nitrogen (BUN) and serum creatinine assay kits were purchased from Bioassay system (USA).

\section{Experimental Design}

Twenty-four male Wistar albino rats were used in this study. The animals were randomly divided into four groups, 6 animals in each. The first group (Control) was administered the vehicle (castor oil) of CsA intraperitoneal (i.p.) daily for 21 days. The second group received CsA [25 mg/kg/day i.p.] daily for 21 days (Pari and Sivasankari, 2008). The third group was administered WGO [900mg/kg/day by oral gavage] (Abd El-Hameed et al., 2013) 5 days before and concurrently during CsA administration daily for 21 days. The fourth group received WGO daily for 21 days. Twenty-four hours after the last treatment, blood samples were collected for the determination of serum levels of creatinine, BUN as well as IL-2. After terminal bleeding, animals were sacrificed by cervical dislocation. The left kidney was dissected immediately after death, washed with ice cold phosphate buffered saline (PBS) and kept at $-20^{\circ} \mathrm{C}$ till used. The right kidney was fixed in $10 \%$ neutral-buffered formal saline for histopathological investigation. 


\section{Assessment of BUN and Serum creatinine}

BUN and serum creatinine levels were determined by commercial kits according to the manufacturer's instructions (Bioassay system, USA).

\section{Assessment of Serum IL-2}

The level of IL-2 in serum was determined by enzyme-linked immunosorbent assay (ELISA) according to the manufacturer's instructions (Uscn Life Science Inc, Wuhan, China).

\section{Determination of oxidative damage markers}

Determination of Lipid Peroxides

The level of malondialdehyde (MDA) [the by-product of lipid peroxidation] in renal tissues was measured using a TBARS assay kit according to the manufacturer's instructions (Cell Biolabs, Inc., USA). Briefly, the unknown MDA containing samples or MDA standards are first reacted with thiobarbituric acid (TBA) at $95^{\circ} \mathrm{C}$. After a brief incubation, the samples and standards can be read spectrophotometrically.

Determination of iNOS expression

The protein level of iNOS in renal tissues was determined by enzyme-linked immunosorbent assay (ELISA) according to the manufacturer's instructions (EIAab Science Co., Ltd., China).

Determination of NF- $\mathrm{NB}$ expression

The level of Total NF- $\kappa \mathrm{B}$ in renal tissues was determined by enzyme-linked immunosorbent assay (ELISA) according to the manufacturer's instructions (EIAab Science Co., Ltd., China).

\section{Determination of endogenous antioxidants}

\section{Determination of GSH}

GSH in renal tissues was determined by colorimetric assay according to the manufacturer's instructions (Oxford biomedical research, Oxford MI, USA). Briefly, the method is based on the reaction of GSH with Ellman's reagent (5, 5'-dithiobis-2-nitrobenzoic acid (DTNB)) which gives rise to a product that can be quantified spectrophotometrically at $412 \mathrm{~nm}$.

\section{Determination of SOD}

SOD activity in renal tissues was determined by assay kit according to the manufacturer's instructions (Trevigen, USA). In Trevigen's superoxide dismutase assay, superoxide radicals generated from the conversion of xanthine to uric acid and hydrogen peroxide by xanthine oxidase (XOD), converts nitroblue tetrazolium (NBT) to NBT-diformazan. NBT-diformazan absorbs light at $550 \mathrm{~nm}$. SODs reduce superoxide radical concentrations and thereby lower the rate of NBT-diformazan formation. The extent of reduction in the appearance of NBTdiformazan is a measure of SOD activity.

Determination of CAT activity

CAT activity in renal tissues was determined by enzyme-linked immunosorbent assay (ELISA) according to the manufacturer's instructions (EIAab Science Co., Ltd., China). 


\section{Histopathological Examination}

Kidney specimens from all animals were dissected immediately after death, and fixed in $10 \%$ neutral-buffered formal saline for at least 72 hours. All the specimens were washed in tap water for half an hour and then dehydrated in ascending grades of alcohol, cleared in xylene and embedded in paraffin. Serial sections of $6 \mu \mathrm{m}$ thick were cut and stained with Haematoxylin and eosin (Drury and Walligton, 1980) for histopathological investigation.

\section{Statistical Analysis}

Results are expressed as means \pm SD. Statistical analysis was performed using Student's $t$ test and for multiple comparisons the ANOVA test for significance. $P$-values below 0.05 were considered as indication for statistically significant differences between conditions compared.

\section{RESULTS \& DISCUSSION}

CsA is one of the most important immunosuppressive agents that are commonly used in organ transplantation and in the treatment of autoimmune diseases. However, the clinical use of CsA is strongly limited by acute and chronic nephrotoxicity which remain a major clinical problem. The mechanisms of CsA-induced nephrotoxicity are still not fully elucidated. It has been demonstrated that over production of ROS and consequently oxidative stress plays a major role in CsA-induced renal damage (Ichikawa et al., 1994; Serino et al., 1994; Akool et al., 2008). Previously, it has been reported that antioxidants have the ability to attenuate nephrotoxicity induced by CsA (Burdmann et al., 2003; Parra et al., 2003; Rezzani et al., 2005; Capasso et al., 2008). WGO was found to contain the highest content of the most powerful natural antioxidant vitamin $\mathrm{E}$ than any other natural source (Shurpalekar and Rao, 1977; Wolf et al., 1998; Ohkatsu et al., 2001). Recently, it has been reported that WGO intake results in a rapid increase in the content of vitamin $\mathrm{E}$ in different rat tissues and gives high protection for these tissues against oxidative damage (Mehranjani et al., 2007; Field et al., 2008). In order to investigate the potential protective effect of WGO against CsA-induced nephrotoxicity, male Wistar albino rats were received either CsA, WGO or WGO 5 days before and concurrently during CsA administration daily for 21 days. In agreement with previous studies (Mason, 1990; Abdelsattar, 2013), treatment of rats with CsA resulted in a decline in renal function as indicated by significant increase in BUN (Fig. 1A) and serum creatinine level (Fig. 1B). However, concomitant administration of WGO along with CsA improved the renal function as indicated by significant decrease in BUN (Fig. 1A) and serum creatinine level (Fig. 1B) compared with CsA alone-treated rats. Alterations in renal function and structural damage have been shown to be associated with lipid peroxidation induced by CsA (Parra et al., 2003; Wongmekiat et al., 2008). In the present study, treatment of rats with CsA significantly induced lipid peroxidation as indicated by an increase in the by-product of lipid peroxidation malondialdehyde (Fig. 2A). On the other hand, lipid peroxidation is significantly attenuated in animals treated with CsA in combination with WGO as compared to CsA alone treated animals (Fig. 2A). Previously, superoxide radical has been shown to be induced by CsA in renal cells (Parra et al., 1998; Raymond et al., 2003; Vetter et al., 2003). Furthermore, the highly reactive peroxynitrite $\left(\mathrm{ONOO}^{-}\right)$that is usually produced by the reaction between nitric oxide (NO) and superoxide $\left(\mathrm{O}_{2}{ }^{-}\right)$has been demonstrated to be induced 
A

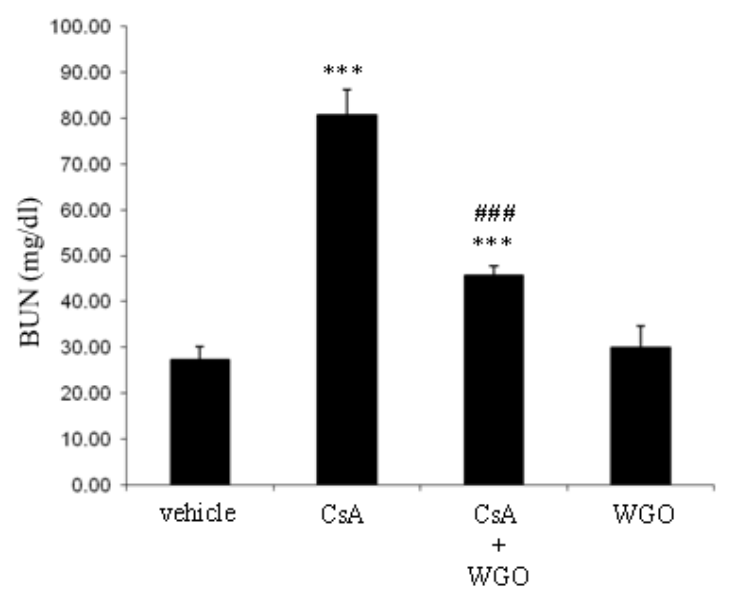

B

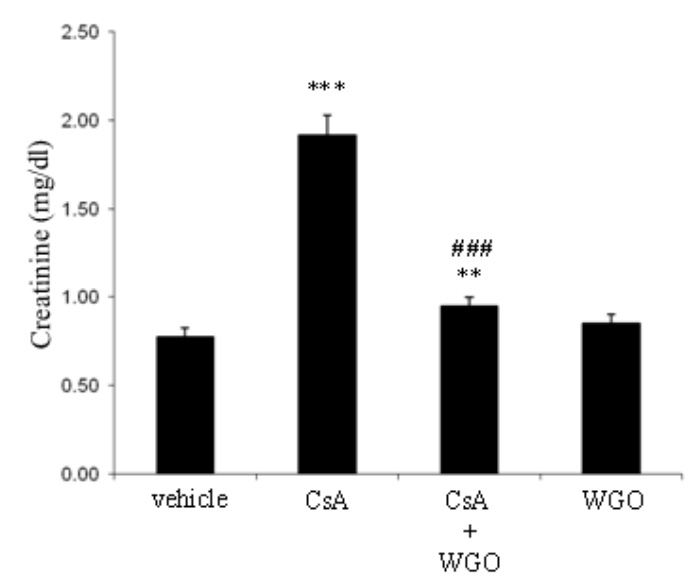

Figure 1. Effects of cyclosporin and/or wheat germ oil on BUN (A) and serum creatinine (B) in male Wistar albino rats. Data represent means \pm S.D. $(\mathrm{n}=6)$, ** $p<0.01$, *** $p<0.001$ versus control, \#\#\# $p<0.001$ versus CsA alone-treated animals.

by CsA in the kidney (Amudha et al., 2006; Ramzy et al., 2006; Jennings et al., 2007; Uz et al., 2008) and involved in renal cellular damage (Josephine et al., 2007). Moreover, it has been reported that CsA-induced renal injury is associated with induction of the pro-oxidant enzyme iNOS (Navarro-Antolín et al., 2007) that catalyze the production of NO. Therefore, the involvement of iNOS in the renal toxicity induced by CsA was investigated. As shown in Fig 2B, treatment of rats with CsA significantly induced iNOS expression. On the other hand, administration of WGO along with CsA significantly attenuated iNOS expression induced by CsA (Fig. 2B). The transcription factor $\mathrm{NF}-\kappa \mathrm{B}$ has been reported to be involved in the transcription of the inflammatory enzyme iNOS and other inflammatory genes in response to oxidative stress (Nanxin and Karin, 1999; Tak and Firestein, 2001; Aktan, 2004). Thus, the involvement of NF- $\mathrm{KB}$ in CsA-induced renal damage has also been investigated. As shown in Fig. 2C, CsA significantly induced NF- $\kappa \mathrm{B}$ expression. However, NF- $\kappa \mathrm{B}$ expression in animals treated with CsA in combination with WGO was highly reduced compared to CsA alone treated animals. (Fig. 2C). An efficient endogenous antioxidant defense system operates to scavenge the reactive oxygen species. The most important endogenous antioxidants are GSH, SOD and CAT. GSH plays a major role in cells protection against oxidative damage and detoxification of xenobiotics including CsA (Meister and Anderson, 1983; Inselmann et al., 1994). Therefore, the renal content of GSH was investigated. In agreement with many studies (Anjaneyulu et al., 2003; Hagar et al., 2006; Wongmekiat et al., 2008), treatment of rats with CsA produced a significant decrease in renal GSH level (Fig. 3A). On the other hand, concomitant administration of WGO along with CsA significantly increased the level of renal GSH as compared to CsA alone-treated animals (Fig. 3A). Also, SOD and CAT play 

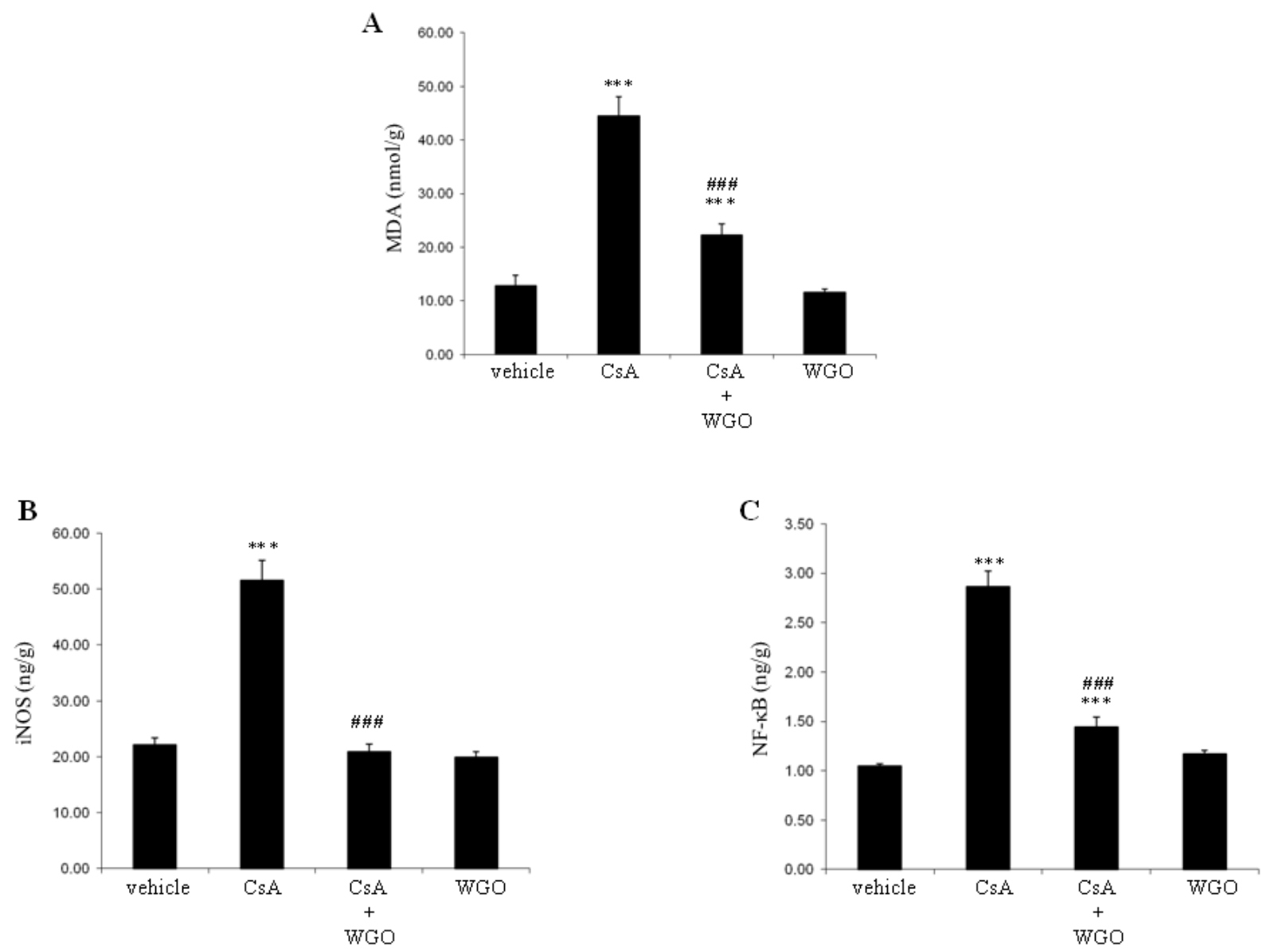

Figure 2. Effects of cyclosporin and/or wheat germ oil on renal content of MDA (A) as well as iNOS (B) and NF-kB expression $(\mathbf{C})$ in male Wistar albino rats. Data represent means \pm S.D. $(\mathrm{n}=6)$, $* * * p<0.001$ versus control, \#\#\# $p<0.001$ versus CsA alone-treated animals.

a major role in cells protection against oxidative damage by scavenging ROS from the cell where SOD metabolizes superoxide radical into hydrogen peroxide (less toxic) that can be detoxified by catalase, which converts $\mathrm{H}_{2} \mathrm{O}_{2}$ into $\mathrm{H}_{2} \mathrm{O}$ and $\mathrm{O}_{2}$ (Deisseroth and Dounce, 1970; McCord et al., 1971) . Therefore, the renal activities of SOD and CAT were investigated. In agreement with previous findings (Anjaneyulu et al., 2003; Hagar et al., 2006; Uz et al., 2011), treatment of rats with CsA produced a significant decrease in the levels of the antioxidant enzymes SOD (Fig. 3B) and CAT (Fig. 3C). However concomitant administration of WGO along with CsA significantly increased the renal activities of the antioxidant enzymes SOD (Fig.3B) and CAT (Fig. 3C) as compared to CsA alone-treated group. Moreover, histopathological examination showed sever damage of the renal tissue in CsA alone-treated rats as indicated by interstitial hemorrhage, disrupted glomerular basement membrane \& hyaline deposition of the blood vessels (Fig. 4B). However, concomitant administration of WGO along with CsA improved these histopathological changes to a great extent as indicated by improvement in the glomerular damage (the glomeruli don't have any noticed change) and decrease in the interstitial hemorrhage (Fig. 4C). Finally, to test whether the immunosuppressive effects of CsA would also be affected in the presence of WGO, the serum level of interleukin-2 (IL-2) that is usually inhibited by CsA (Matsuda and Koyasu, 

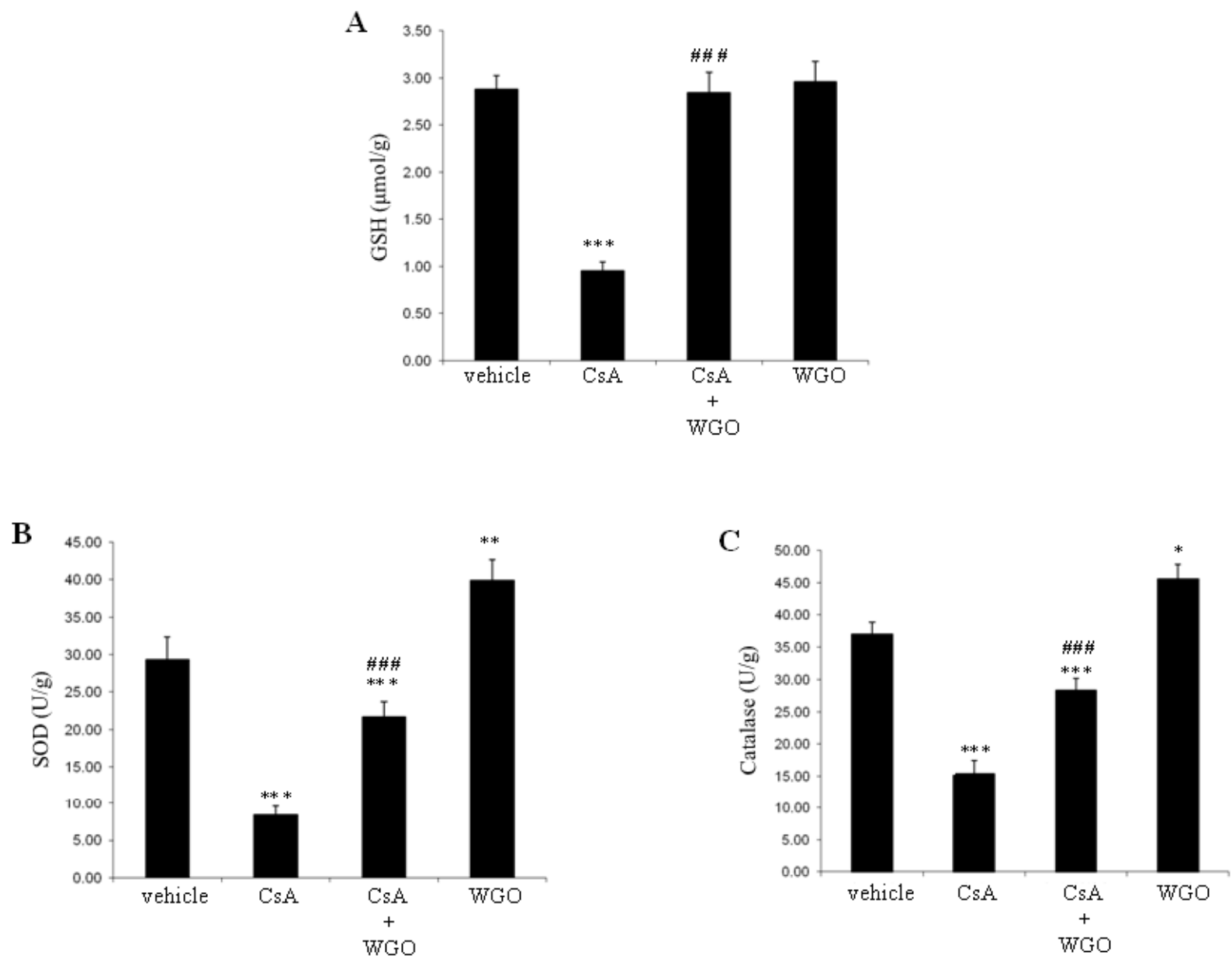

Figure 3. Effects of cyclosporin and/or wheat germ oil on renal content of GSH (A) as well as renal enzymatic activities of SOD $(B)$ and CAT $(C)$ in male Wistar albino rats. Data represent means \pm S.D. $(n=6)$, $* p<0.05, * * p<0.01$ and ${ }^{* * *} p<0.001$ versus control, \#\#\# $p<0.001$ versus CsA alone-treated animals.

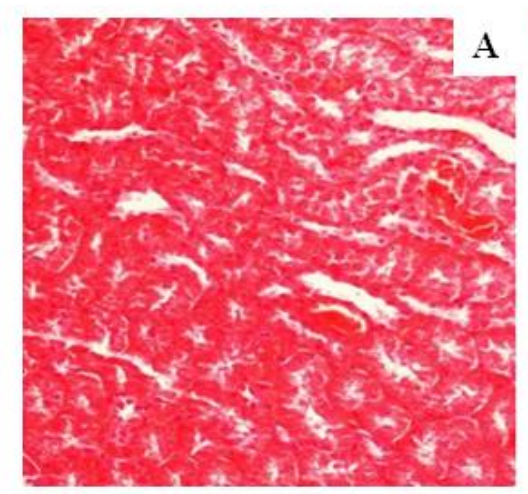

Control

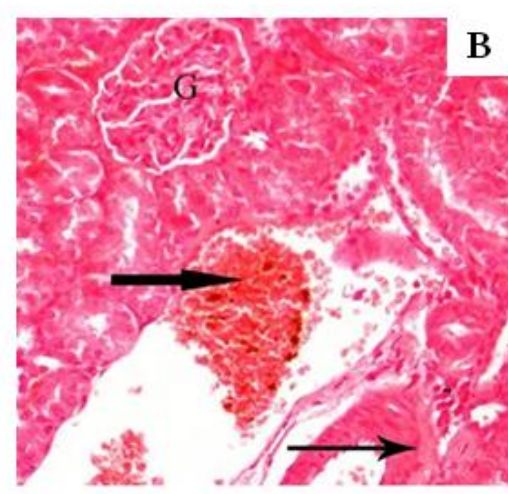

CsA

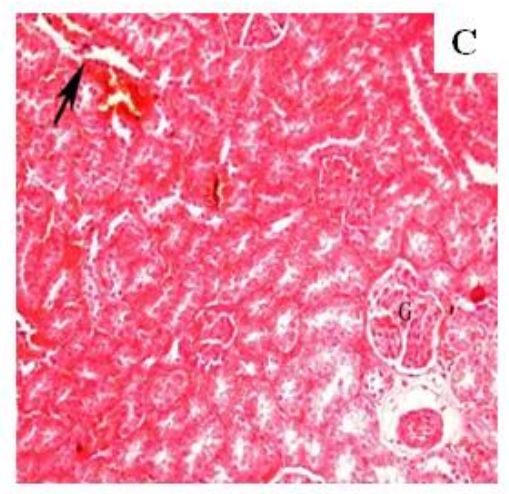

$\mathrm{CsA}+\mathrm{WGO}$

Figure 4. A. A photomicrograph of a section of the kidney of a control rat showing the normal structure of the tissue. (Hx \& E. X 100). B. A photomicrograph of a section of the kidney of cyclosporin alone-treated rats showing sever damage of the renal tissue at which there are interstitial hemorrhage (thick arrow) with disrubted glomerular basement membrane $(\mathrm{G})$, as well as mild to moderate thickened blood vessels due to hyaline deposition(thin arrow). (Hx. \& E. X 200). C. A photomicrograph of a section of the kidney of rats received cyclosporin + wheat germ oil showing mild interstitial hemorrhage (arrow) while the glomeruli don't have any noticed change (G). (Hx \& E. X 100). 


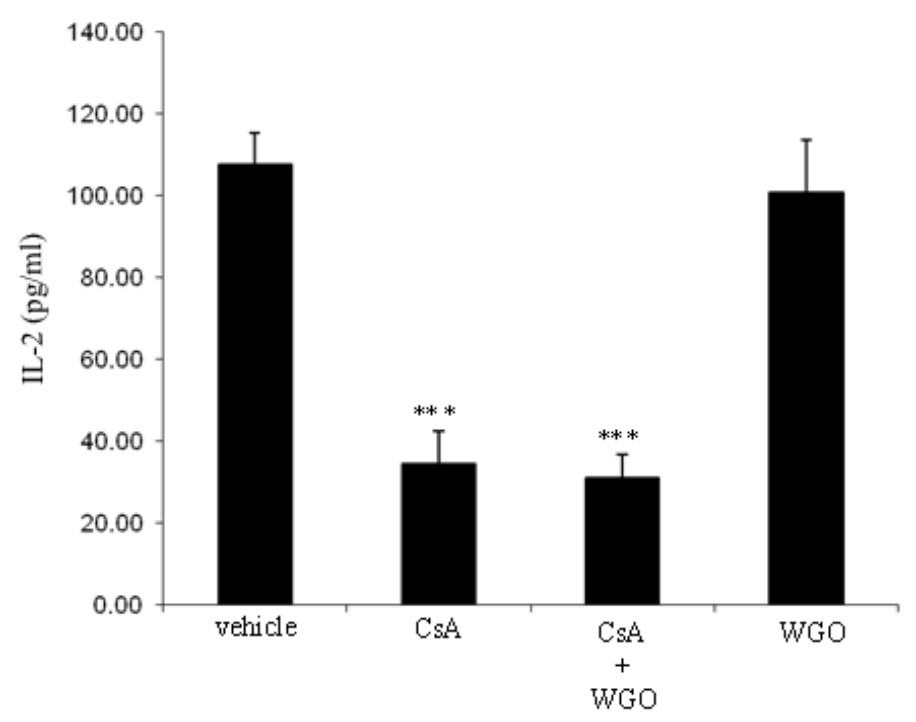

Figure 5. Effects of cyclosporin and/or wheat germ oil on serum level of IL-2 in male Wistar albino rats. Data represent means \pm S.D. $(\mathrm{n}=6), * * * p<0.001$ versus control.

2000) was evaluated. As shown in fig 5, treatment of rats with CsA produced a significant decrease in the level of IL-2 as expected but most interestingly this inhibition of IL-2 by CsA was not changed in the presence of WGO indicating that the immunosuppressive effect of CsA was not affected by WGO.

In conclusion, the present work demonstrates that CsA administration results in oxidative damage as indicated by an increase in lipid peroxidation, iNOS and NF- $\kappa \mathrm{B}$ expression as well as severe damage of the renal tissue with impairment of renal function as indicated by significant increase in BUN and serum creatinine levels. However, concomitant administration of WGO along with CsA improved not only the impairment of renal function but also the histopathological changes induced by CsA via inhibition of the oxidative damage markers lipid peroxidation, iNOS, and NF- $\kappa \mathrm{B}$ expression. This inhibition of the oxidative damage markers was associated with induction of the most important endogenous antioxidants GSH, SOD and CAT which play a major role in cells protection against oxidative damage. Furthermore, the present work demonstrates that the immunosuppressive effect of CsA was not affected in the presence of WGO. Finally, the findings of the present study suggest that concomitant use of WGO might be useful in reducing renal toxicity induced by CsA.

\section{REFERENCES}

Abd El-Hameed AM, Soliman HA and Abd El-Reheem ES. (2013): Protective role of wheat germ oil in clozapine-induced oxidative stress and biochemical alterations in liver of male albino rats. J. Am. Sci. 9: 268-274.

Abdelsattar MH. (2013): Garlic oil as an effective protective agent against CsA-induced nephrotoxicity in rats. Int. J. Med. Arom. Plants 3: 85-92. 
Akool El-S, Doller A, Babelova A, Tsalastra W, Moret K, Schaefer L, Pfeilschifter J and Eberhardt W. (2008): Molecular mechanisms of TGF beta receptor-triggered signalling cascades rapidly induced by the calcineurin inhibitors cyclosporin $\mathrm{A}$ and FK506. J. Immunol. 181: 2831-45.

Aktan F. (2004): iNOS-mediated nitric oxide production and its regulation. Life Sciences 75: 639-653.

Alessandri C, Pignatelli P, Loffredo L, Lenti L, Del Ben Roberto CM, Perrone A, Ferro D, Angelico F and Violi F. (2006): Alpha-linolenic acid-rich wheat germ oil decreases oxidative stress and CD40 Ligandin patients with mild hypercholesterolemia. Arterioscler. Thromb. Vasc. Biol. 26: 2577-2578.

Amudha G, Josephine A and Varalakshmi P. (2006): Role of lipoic acid in reducing the oxidative stress induced by cyclosporine A. Clin. Chim. Acta. 372: 134-139.

Anjaneyulu M, Tirkey N and Chopra K. (2003): Attenuation of cyclosporine-induced renal dysfunction by catechin: possible antioxidant mechanism. Ren. Fail. 25: 691-707.

Burdmann EA, Andoh TF, Yu L and Bennett WM. (2003): Cyclosporine nephrotoxicity. Semin Nephrol. 23: 465-76.

Capasso G, Di Gennaro CI, Della RF, Manna C, Ciarcia R, Florio S, Perna A, Pollastro RM, Damiano S, Mazzoni O, Galletti P and Zappia V. (2008): In vivo effect of the natural antioxidant hydroxytyrosol on cyclosporine nephrotoxicity in rats. Nephrol. Dial. Transplant. 23: 1186-1195.

Deisseroth A and Dounce AL. (1970): Catalase: Physical and chemical properties, mechanism of catalysis, and physiological role. Physiol. Rev. 50: 319-375.

Drury RVA and Walligton EA. (1980): Carltons Histological techniques, $5^{\text {th }}$ ed, Oxford University Press, New York, Pronto, pp. 206.

Fellstrom B. (2004): Cyclosporine nephrotoxicity. Transplant. Proc. 36: 220-223.

Field R, Verghese M, Walker LT and Boateng J. (2008): Feeding wheat germ meal and wheat germ oil reduced azoxymethane-induced aberrant crypt foci in fisher 344 male rats. Int. J. Cancer Res. 4: 127-136.

Hagar HH, El Etter E and Arafa M. (2006): Taurine attenuates hypertension and renal dysfunction induced by cyclosporine A in rats. Clin. Exp. Pharmacol. Physiol. 33: 189-196.

Ichikawa I, Kiyama S and Yoshioka T. (1994): Renal antioxidant enzymes: their regulation and function. Kidney Int. 45: 1-9.

Inselmann G, Lawerenz HU, Nellessen U and Heidemann HT. (1994): Enhancement of cyclosporin A induced hepato- and nephrotoxicity by glutathione depletion. Eur. J. Clin. Invest. 24: 355-359.

Jennings P, Koppelstaetter C, Aydin S, Abberger T, Wolf AM, Mayer G and Pfaller W. (2007): Cyclosporine A induces senescence in renal tubular epithelial cells. Am. J. Physiol. Renal Physiol. 293: 831-838. 
Josephine A, Amudha G, Veena CK, Preetha SP and Varalakshmi P. (2007): Oxidative and nitrosative stress mediated renal cellular damage induced by cyclosporine A: role of sulphated polysaccharides. Biol. Pharm. Bull. 30: 1254-1259.

Mason J. (1990): The pathophysiology of Sandimmun (cyclosporin) in man and animals. Pediatr nephrol. 4: 554-574.

Matsuda S. and Koyasu S. (2000): Mechanisms of action of cyclosporine. Immunopharmacology 47: 119-125.

McCord JM, Keele BB Jr and Fridovich I. (1971): An enzyme-based theory of obligate anaerobiosis: the physiological function of superoxide dismutase. Proc. Natl. Acad. Sci. USA 68: 1024-1027.

Mehranjani MS, Abnosi MH and Mahmodi M. (2007): Preventing effects of wheat germ oil on sex hormones, liver enzymes, lipids and proteins in rat serum following treatment with pnonylphenol. J. Biol. Sci. 7: 1408-1411.

Meister A and Anderson ME. (1983): Glutathione. Ann. Rev. Biochem. 52: 711-760.

Mihatsch MJ, Kyo M, Morozumi K, Yamaguchi Y, Nickeleit V and Ryffel B. (1998): The side-effects of ciclosporine-A and tacrolimus. Clin. Nephrol. 49: 356-363.

Nanxin LI and Karin M. (1999): Is NF- $\kappa B$ the sensor of oxidative stress? FASEB J. 13: 1137- 1143.

Navarro-Antolín J, Redondo-Horcajo M, Zaragoza C, Alvarez-Barrientos A, Fernández AP, León-Gómez E, Rodrigo J and Lamas S. (2007): Role of peroxynitrite in endothelial damage mediated by Cyclosporine A. Free Radic. Biol. Med. 42: 394-403.

Ohkatsu Y, Kajiyama T, and Arai Y. (2001): Antioxidant activities of tocopherols. Polymer degradation and stability 72: 303-311.

Parra T, de Arriba G, Arribas I, Perez de Lema G, Rodriguez-Puyol D and RodriguezPuyol M. (1998): Cyclosporine A nephrotoxicity: role of thromboxane and reactive oxygen species. J. Lab. Clin. Med. 131: 63-70.

Pari L and Sivasankari R. (2008): Effect of ellagic acid on cyclosporine A-induced oxidative damage in the liver of rats. Fundam. Clin. Pharmacol. 22: 395-401.

Parra T, Conejo García JR, Carballo Alvarez AF and de Arriba G. (2003): Antioxidant nutrients protect against cyclosporine A nephrotoxicity. Toxicology 189: 99-111.

Ramzy D, Rao V, Tumiati LC, Xu N, Miriuka S, Delgado D and Ross HJ. (2006): Role of endothelin-1 and nitric oxide bioavailability in transplant-related vascular injury: comparative effects of rapamycin and cyclosporine. Circulation 114: I214-9.

Raymond MA, Mollica L, Vigneault N, Désormeaux A, Chan JS, Filep JG and Hébert MJ. (2003): Blockade of the apoptotic machinery by cyclosporin A redirects cell death toward necrosis in arterial endothelial cells: regulation by reactive oxygen species and cathepsin D. FASEB J. 17: 515-7.

Rezzani R, Rodella L, Buffoli B, Goodman AA, Abraham NG, Lianos EA and Bianchi R. (2005): Change in renal heme oxygenase expression in cyclosporine A-induced injury. J. Histochem. Cytochem. 53: 105-12. 
Schreiber SL and Crabtree GR. (1992): The mechanism of action of cyclosporine A and FK506. Immunol. Today 13: 136-142.

Serino F, Grevel J, Napoli KL, Kahan BD and Strobel HW. (1994): Oxygen radical formation by the cytochrome P450 system as a cellular mechanism for cyclosporine toxicity. Transplant. Proc. 26: 2916-7.

Shurpalekar SR and Rao PH. (1977): Wheat germ. Adv. Food Res. 23: 187-304.

Sjovall O, Virtalaine T, Lapvetelainen A and Kallio H. (2000): Development of rancidity in wheat germ analyzed by headspace gas chromatography and sensory analysis. J. Agr. Food Chem. 48: 3522-3527.

Tak PP and Firestein GS. (2001): NF-кB: a key role in inflammatory diseases, J. Clin. Invest. 107: 7-11.

Tariq M, Morais C, Sobki S, Alsulaiman M and Alkhader A. (1999): N-acetylcysteine attenuates cyclosporin-induced nephrotoxicity in rats. Nephrol. Dial. Transplant. 14: 923-929.

Uz E, Bayrak O, Uz E, Kaya A, Bayrak R, Uz B, Turgut FH, Bavbek N, Kanbay M and Akcay A. (2008): Nigella sativa oil for prevention of chronic cyclosporine nephrotoxicity: an experimental model. Am. J. Nephrol. 28: 517-522.

Uz E, Uz B, Kaya A, Akdeniz D, Ruzgaresen NB, Uz E, Turgut FH, Bayrak R and Akcay A. (2011): Protective Effect of Erdosteine on Cyclosporine Induced Chronic Nephrotoxicity in Rats. Nephro-Urol Mon. 4: 280-284.

Vetter M, Chen ZJ, Chang GD, Che D, Liu S and Chang CH. (2003): Cyclosporin A disrupts bradykinin signaling through superoxide. Hypertension 41: 1136-42.

Wolf R, Wolf D and Ruocco V. (1998): Vitamin E: the radical protector. J Eur. Acad. Dermatol. Venereol. 10: 103-117.

Wongmekiat O, Leelarugrayub $\mathrm{N}$ and Thamprasert K. (2008): Beneficial effect of shallot (Allium ascalonicum L.) extract on cyclosporine nephrotoxicity in rats. Food Chem. Toxicol. 46: 1844-50.

Zhu K, Zhou HM and Qian HF. (2006): Proteins extracted from defatted wheat germ, nutritional and structural properties. Cereal Chem. 83: 69-75. 


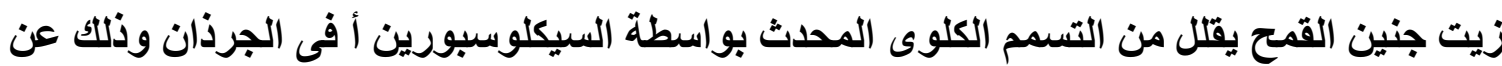

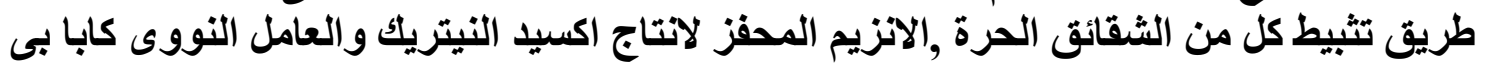

للسيدة الاكتورة

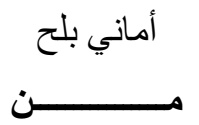

قسم علم الأدويه و السموم- كلية الصيدلة (بنات)- جامعة الأز هر

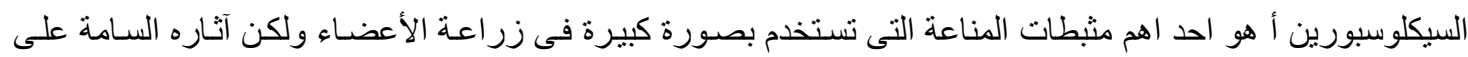

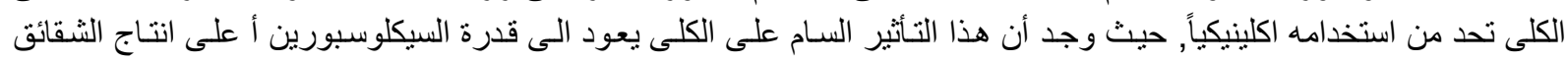

استهدفت هذه الدر اسة بحث مدى امكانية الحد من التسمم الكلوى المحدث بو اسطة السيكلوسبورين أ باستخدام زيت جنين القمح, كمـا استهدفت ايضاً معرفة الميكانيكية الجزيئية للحد من التسمم الكلوى بو اسطة زيت جنين القمح.

وقد اتضح من هذه الدراسة ان استعمال السيكلوسبورين أ أدى الى زيادة الكرياتين واليوريا فى الدام. كما ادى استعمال السيكلوسبورين

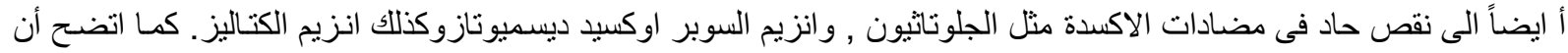

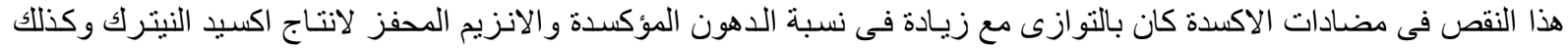

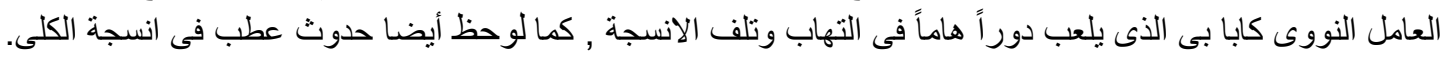

وقد وجد من خلال هذه الدراسة أن استعمال زيت جنين القمح أدى الى تحسن مستوى الكرياتين و اليوريا فى الدم, كما أدى الى زيادة الزياد

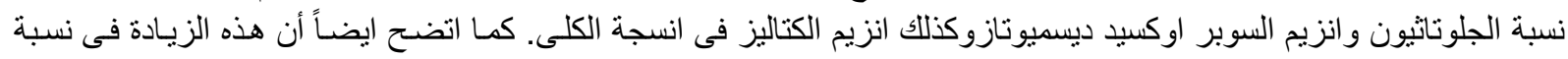

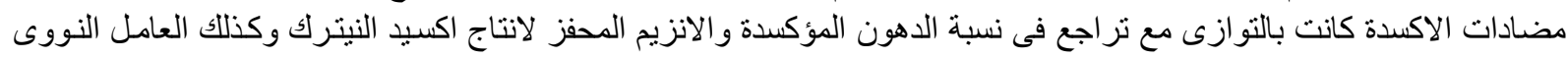

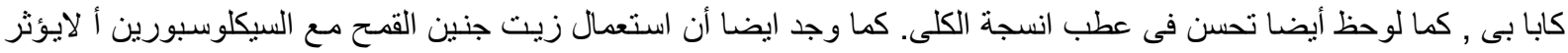
على كفائة السيكلو سبورين أ كمثبط للمناعة.

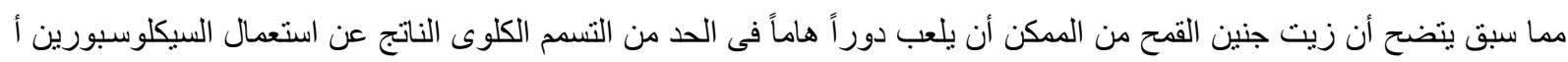

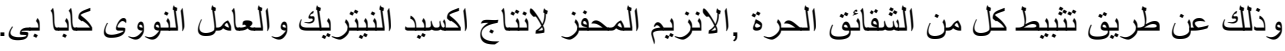

